\title{
Effects of interferon-alpha on hippocampal neurogenesis and behavior in common marmosets
}

\author{
Naoko Kaneko ${ }^{1,2^{*}}$, Sayuri Nakamura ${ }^{1}$ and Kazunobu Sawamoto ${ }^{1,2^{*}}$ (D)
}

\begin{abstract}
In many mammalian species, the production of new neurons in the hippocampal dentate gyrus continues throughout life. Previous studies using rodents suggest that adult-born neurons are involved in memory and cognition tasks and mood regulation. Interferon-alpha (IFNa), a proinflammatory cytokine used for the treatment of chronic viral hepatitis and malignancies, frequently causes depressive symptoms in patients and animals, including non-human primates. We have previously demonstrated that chronic IFNa treatment decreases hippocampal neurogenesis in mice. Here, we investigated the effects of four-week human pegylated IFNa treatment on hippocampal neurogenesis and behavior in common marmosets. Continuous monitoring of voluntary activity levels using an actigraphy device suggested that adaptive ability is impaired in IFNa-treated animals. Analyses of BrdUlabeled cells expressing a marker for immature or mature neurons revealed a significant reduction in the number of new neurons in the hippocampus of IFNa-treated animals. These data indicate that chronic human IFNa treatment causes behavioral changes and a decrease in hippocampal neurogenesis in common marmosets.
\end{abstract}

Keywords: Adult neurogenesis, Common marmoset, Dentate gyrus, Depression, Interferon-alpha, Primate, Proliferation

\section{Main text}

In many mammalian species, neural stem cells in the hippocampal dentate gyrus continuously produce new neurons throughout life. These new neurons, which possess distinct electrophysiological properties from those of pre-existing neurons, contribute to hippocampaldependent memory and cognition and have been implicated in stress responses and depressive behaviors in rodents [1]. The degree of adult neurogenesis in the adult human brain is controversial [2,3], largely because of ethical and methodological limitations of human studies. Studies using non-human primates, whose brains have

\footnotetext{
* Correspondence: naokoka@med.nagoya-cu.ac.jp; sawamoto@med.nagoyacu.ac.jp

${ }^{1}$ Department of Developmental and Regenerative Neurobiology, Institute of Brain Science, Nagoya City University Graduate School of Medical Sciences, 1 Kawasumi, Mizuho-cho, Mizuho-ku, Nagoya, Aichi 467-8601, Japan Full list of author information is available at the end of the article
}

structural and functional similarities with the human brain, should provide useful information for understanding the mechanisms and functions of hippocampal neurogenesis in primates.

Interferon-alpha (IFN $)$ has been used for the treatment of chronic viral hepatitis and several malignancies. However, it causes depression in about $30 \%$ of all treated patients, which frequently prevents the completion of treatment [4]. Furthermore, IFN $\alpha$ treatment also induces depression-like behavioral changes in rodents [5-7] and non-human primates $[8,9]$. Impaired monoamine signaling and inflammatory responses are involved in IFN $\alpha$ induced depression, although their precise mechanisms are still unclear. We have previously reported that IFN $\alpha$ treatment decreases hippocampal neurogenesis and induces depression-like behavioral changes in mice via type-1 IFN receptors in the central nervous system [5]. 


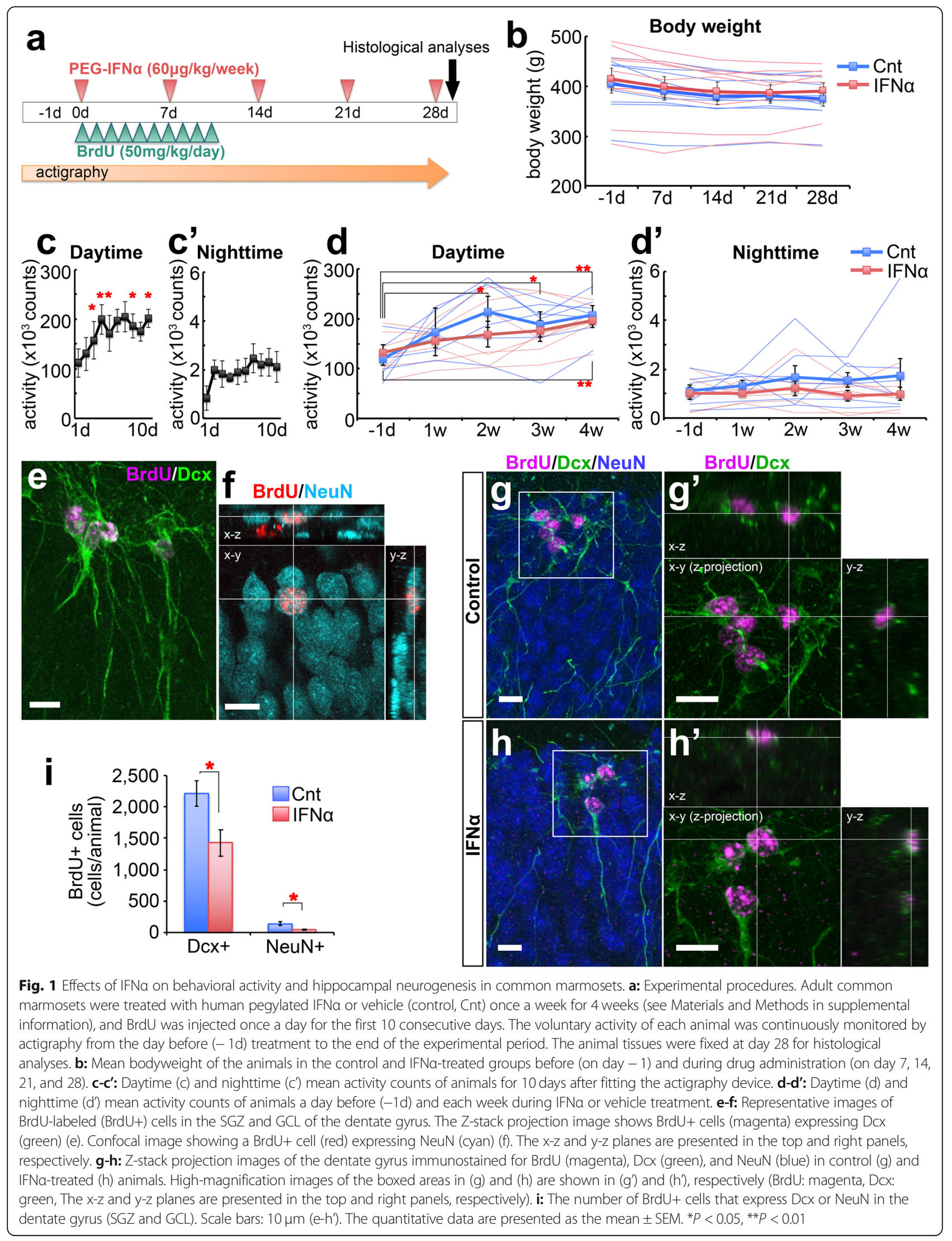


IFN $\alpha$ also reduces neurogenesis of human hippocampal neural progenitors in vitro [10]. Here, we investigated the effects of chronic IFN $\alpha$ treatment on behavior and hippocampal neurogenesis in common marmosets (Callithrix jacchus), which are small-bodied monkeys established as laboratory animals for preclinical research.

Considering clinical protocols, we subcutaneously injected human pegylated IFN $\alpha$ or vehicle once a week for four weeks into young-adult male and female common marmosets (Fig. 1a, Additional file 1). To label newly-generated neurons, BrdU $(50 \mathrm{mg} / \mathrm{kg} /$ day $)$ was intraperitoneally administrated once a day for ten consecutive days from the day of the first IFN $\alpha$ treatment. The body weights showed no significant difference at any time point between the vehicle-treated (control) and IFN $\alpha$-treated groups (Fig. 1b). The voluntary activity of each animal was continuously monitored with a small actigraphy device. A pilot study without drug injections showed that the daytime activity levels gradually increased after the device was fitted and reached a plateau within several days due to adaptation (Fig. 1c-c'). Therefore, we fitted the device two days before the first drug administration. However, repeated injections in control animals delayed adaptation, leading to increases in daytime activity in the second week and thereafter (Fig. 1d). IFNo-treated animals, however, showed no such increases until the third week (Fig. 1d), suggesting that their adaptive ability was impaired. These data also suggest that IFN $\alpha$ decreased daytime activity, similar to symptoms observed in patients, although we did not detect any statistical significance because of large interindividual variance. IFN $\alpha$ treatment frequently causes insomnia in patients; however, the IFNo-treated marmosets did not show statistically-significant alterations in nighttime activity (Fig. 1d'), possibly due to the differences in sleep patterns among primates [11].

We next examined the distribution of BrdU-labeled $(\mathrm{BrdU}+)$ cells in the subgranular zone (SGZ), where neural stem/progenitor cells reside, and granular cell layer (GCL), the destination of newly-generated neurons, of the hippocampal dentate gyrus. Most BrdU+ cells were located in the inner layer of the GCL and expressed the immature neuronal marker, doublecortin (Dcx) (Fig. 1e). BrdU+ cells expressing the mature neuronal marker, neuronal nuclei (NeuN), were observed only at low frequency (Fig. 1f) because these neurons take longer to mature in primates compared with those in the rodent GCL $[12,13]$. The numbers of BrdU+Dcx + cells and BrdU+NeuN + cells in these areas were significantly decreased in the IFN $\alpha$ treated group compared with those in the control group (Fig. 1g-i). Taken together, IFN $\alpha$ treatment significantly suppressed behavioral activity and diminished hippocampal neurogenesis in common marmosets, consistent with our previous studies using rodents $[5,6]$.
To analyze the impact on slow neuronal maturation in primates more precisely, a longer IFN $\alpha$ treatment is needed. However, we did not extend the treatment period because repeated injections of human IFN $\alpha$ in common marmosets can lead to the production of antibodies that neutralize its biological activity. Therefore, it is likely that the IFN $\alpha$-induced behavioral changes observed in this study did not result from decreased neurogenesis, but were associated with other effects such as acute inflammation. However, we cannot exclude the possibility that adult-born immature neurons play some role in hippocampal function in common marmosets. Given the differences in spatiotemporal distribution and biological properties of adult-born hippocampal neurons between rodents and primates [13, 14], their involvement in mood regulation may also be different. Furthermore, physical exercise promotes hippocampal neurogenesis [15]; therefore, it is also possible that the higher level of neurogenesis in the control animals compared with IFN $\alpha$-treated animals might be caused by their earlier increase in voluntary activity during the experimental period (Fig. 1d). Further studies using common marmosets will lead to a better understanding of the effects of IFN $\alpha$ on mood and neurogenesis in primates.

\section{Supplementary information}

Supplementary information accompanies this paper at https://doi.org/10. 1186/s13041-020-00639-9.

Additional file 1. Materials and Methods

Abbreviations

IFNa: Interferon-alpha; Dcx: Doublecortin; NeuN: Neuronal nuclei; SGZ: Subgranular zone; GCL: Granule cell layer

\section{Acknowledgments}

We thank Hisashi Oishi, Ichiro Miyoshi, Masayuki Nishio, and Yukio Wakimoto (Nagoya City University) for animal care, Yuka Takeda and Kazunaga Hattori (Nagoya City University) for technical support, Kazuya Kuboyama (Nagoya City University) for critical reading, and Trent Rogers (Edanz Group) for editing a draft of this manuscript.

\section{Authors' contributions}

N.K. and S.N. performed experiments. N.K. and S.N. analyzed the data. N.K. and K.S. designed the experiments and wrote the manuscript. The author(s) read and approved the final manuscript.

\section{Funding}

This study was supported by research grants from the Japan Society for the Promotion of Science/the Japanese Ministry of Education, Culture, Sports, Science and Technology KAKENHI (17H01392, 17H05750, 19H04757,

$19 \mathrm{H} 04785,18 \mathrm{KK} 0213$ [to K.S.], $17 \mathrm{~K} 07114,20 \mathrm{H} 03565$ [to N.K.]), the Japan Agency for Medical Research and Development (JP19bm0704033,

JP19gm1210007 [to K.S.], JP18jm0210060 [to N.K. and K.S.]), a Research Grant from the Japanese Ministry of Health, Labour and Welfare (to N.K. and K.S.), the Funding Program for Next Generation World-Leading Researchers Grant Number LS104 (to K.S.), a Grant-in-Aid for Research at Nagoya City University (to N.K.), and the Takeda Science Foundation (to N.K.). 


\section{Availability of data and materials}

All data required to evaluate the conclusions presented in this study are included in the manuscript or its supplementary information file.

\section{Ethics approval and consent to participate}

All experiments using live animals were performed in accordance with the guidelines and regulations of Nagoya City University.

\section{Consent for publication}

Not applicable.

\section{Competing interests}

The authors declare no competing interests.

\section{Author details}

'Department of Developmental and Regenerative Neurobiology, Institute of Brain Science, Nagoya City University Graduate School of Medical Sciences, 1 Kawasumi, Mizuho-cho, Mizuho-ku, Nagoya, Aichi 467-8601, Japan. ${ }^{2}$ Division of Neural Development and Regeneration, National Institute for Physiological Sciences, 5-1 Higashiyama, Myodaiji, Okazaki, Aichi 444-8787, Japan.

Received: 29 April 2020 Accepted: 19 June 2020

Published online: 26 June 2020

\section{References}

1. Anacker $C$, Hen R. Adult hippocampal neurogenesis and cognitive flexibilitylinking memory and mood. Nat Rev Neurosci. 2017;18(6):335-46.

2. Boldrini M, Fulmore CA, Tartt AN, Simeon LR, Pavlova I, Poposka V, et al. Human hippocampal neurogenesis persists throughout aging. Cell Stem Cell. 2018;22(4):589-99.

3. Sorrells SF, Paredes MF, Cebrian-Silla A, Sandoval K, Qi D, Kelley KW, et al. Human hippocampal neurogenesis drops sharply in children to undetectable levels in adults. Nature. 2018:555(7696):377-81.

4. Lucaciu LA, Dumitrascu DL. Depression and suicide ideation in chronic hepatitis c patients untreated and treated with interferon: prevalence, prevention, and treatment. Ann Gastroenterol. 2015;28(4): 440-7.

5. Zheng L-S, Hitoshi S, Kaneko N, Takao K, Miyakawa T, Tanaka Y, et al. Mechanisms for interferon-a-induced depression and neural stem cell dysfunction. Stem Cell Reports. 2014 Jul;3(1):73-84.

6. Kaneko N, Kudo K, Mabuchi T, Takemoto K, Fujimaki K, Wati H, et al. Suppression of cell proliferation by interferon-alpha through interleukin-1 production in adult rat dentate gyrus. Neuropsychopharmacology. 2006; 31(12):2619-26.

7. Makino M, Kitano Y, Hirohashi M, Takasuna K. Enhancement of immobility in mouse forced swimming test by treatment with human interferon. Eur J Pharmacol. 1998;356(1):1-7.

8. Felger JC, Alagbe O, Hu F, Mook D, Freeman AA, Sanchez MM, et al Effects of interferon-alpha on rhesus monkeys: a nonhuman primate model of cytokine-induced depression. Biol Psychiatry. 2007;62(11): 1324-33.

9. Felger JC, Mun J, Kimmel HL, Nye JA, Drake DF, Hernandez CR, et al. Chronic interferon-a decreases dopamine 2 receptor binding and striatal dopamine release in association with anhedonia-like behavior in nonhuman primates. Neuropsychopharmacology. 2013;38(11):2179-87.

10. Borsini A, Cattaneo A, Malpighi C, Thuret S, Harrison NA, Zunszain PA, et al. Interferon-alpha reduces human hippocampal neurogenesis and increases apoptosis via activation of distinct STAT1-dependent mechanisms. Int J Neuropsychopharmacol. 2018;21(2):187-200.

11. Crofts HS, Wilson S, Muggleton NG, Nutt DJ, Scott EAM, Pearce PC. Investigation of the sleep electrocorticogram of the common marmoset (Callithrix jacchus) using radiotelemetry. Clin Neurophysiol. 2001;112(12): 2265-73.

12. Kohler SJ, Williams NI, Stanton GB, Cameron JL, Greenough WT. Maturation time of new granule cells in the dentate gyrus of adult macaque monkeys exceeds six months. Proc Natl Acad Sci U S A. 2011; 108(25):10326-31.

13. Akter M, Kaneko N, Herranz-Pérez V, Nakamura S, Oishi H. García-Verdugo JM, et al. Cereb Cortex: Dynamic Changes in the Neurogenic Potential in the Ventricular-Subventricular Zone of Common Marmoset during Postnatal Brain Development; 2020.
14. Amrein I, Nosswitz M, Slomianka L, van Dijk RM, Engler S, Klaus F, et al. Septo-temporal distribution and lineage progression of hippocampal neurogenesis in a primate (Callithrix jacchus) in comparison to mice. Front Neuroanat. 2015:9:85.

15. Cooper C, Moon HY, Van Praag H. On the run for hippocampal plasticity. Cold Spring Harb Perspect Med. 2018;8(4):a029736.

\section{Publisher's Note}

Springer Nature remains neutral with regard to jurisdictional claims in published maps and institutional affiliations.
Ready to submit your research? Choose BMC and benefit from:

- fast, convenient online submission

- thorough peer review by experienced researchers in your field

- rapid publication on acceptance

- support for research data, including large and complex data types

- gold Open Access which fosters wider collaboration and increased citations

- maximum visibility for your research: over $100 \mathrm{M}$ website views per year

At $\mathrm{BMC}$, research is always in progress.

Learn more biomedcentral.com/submissions 